\title{
Leucine-rich diet supplementation modulates foetal muscle protein metabolism impaired by Walker-256 tumour
}

\author{
Bread Cruz and Maria CC Gomes-Marcondes*
}

\begin{abstract}
Background: Cancer-cachexia induces a variety of metabolic disorders of protein turnover and is more pronounced when associated with pregnancy. Tumour-bearing pregnant rats have impaired protein balance, which decreases protein synthesis and increases muscle breakdown. Because branched-chain amino acids, especially leucine, stimulate protein synthesis, we investigated the effect of a leucine-rich diet on protein metabolism in the foetal gastrocnemius muscles of tumour-bearing pregnant rats.

Methods: Foetuses of pregnant rats with or without Walker 256 tumours were divided into six groups. During the 20 days of the experiment, the pregnant groups were fed with either a control diet (C, control rats; W, tumour-bearing rats; $\mathrm{Cp}$, rats pair-fed the same normoprotein-diet as the $\mathrm{W}$ group) or with a leucine-rich diet ( $L$, leucine rats; $L W$, leucine tumour-bearing rats; and $L p$, rats pair-fed the same leucine-rich diet as the LW group). After the mothers were sacrificed, the foetal gastrocnemius muscle samples were resected, and the protein synthesis and degradation and tissue chymotrypsin-like, cathepsin and calpain enzyme activities were assayed. The muscle oxidative enzymes (catalase, glutathione-S-transferase and superoxide dismutase), alkaline phosphatase enzyme activities and lipid peroxidation (malondialdehyde) were also measured.
\end{abstract}

Results: Tumour growth led to a reduction in foetal weight associated with decreased serum protein, albumin and glucose levels and low haematocrit in the foetuses of the W group, whereas in the LW foetuses, these changes were less pronounced. Muscle protein synthesis (measured by L-[3H]-phenylalanine incorporation) was reduced in the $\mathrm{W}$ foetuses but was restored in the LW group. Protein breakdown (as assessed by tyrosine release) was enhanced in the $L$ and $W$ groups, but chymotrypsin-like activity increased only in group $W$ and tended toward an increase in the LW foetuses. The activity of cathepsin $\mathrm{H}$ was significantly higher in the $\mathrm{W}$ group foetuses, but the proteolytic calcium-dependent pathway showed similar enzyme activity. In parallel, an intense oxidative stress process was observed only in the group $W$ foetuses.

Conclusions: These data suggested that the proteasomal and lysosomal proteolytic pathways and oxidative stress are likely to participate in the process of foetal muscle catabolism of Walker's tumour-bearing pregnant rats. The present work shows that foetal muscle can be protected by supplementation with a leucine-rich diet.

Keywords: Foetal protein metabolism, Nutritional supplementation, Leucine, Walker tumour, Proteasome

\footnotetext{
*Correspondence: cintgoma@unicamp.br

Laboratory of Nutrition and Cancer, Department of Structural and Functional

Biology, Institute of Biology, State University of Campinas - UNICAMP

Campinas, 13083862 Sao Paulo, Brazil
} 


\section{Background}

Pregnancy concomitant with cancer occurs in approximately one in one thousand women, but this combination is responsible for one-third of all maternal deaths $[1,2]$. Relatively few relevant reports exist in the scientific literature regarding the consequences of tumour growth for the maternal host and the foetal body. Our previous studies showed that tumour-bearing dam rats displayed approximately $70 \%$ reabsorption and $50 \%$ foetal death [3-6]; in this work, we focused on foetal growth because there is little data about the effects on foetal homeostasis and damage when the mother suffers from a tumour [7].

Tumour growth promotes extensive biochemical and metabolic changes in the host organism, leading to the process of cachexia and culminating in deep catabolism of lean mass [8-10]. As a result, the host demonstrates marked weight loss, which is not minimised by forced feeding. To study these all these processes experimentally, Walker-256 tumour is a good experimental model of cachexia $[9,10]$. In addition, pregnancy causes physiological changes that ensure foetal growth and development until the term pregnancy and ensures an adequate energy supply to the foetus and after birth [11]. Additionally, during pregnancy, increased oxidative stress can cause pre-eclampsia and intrauterine foetal growth retardation [12], which may be promoted by tumour development [13].

Branched-chain amino acids (BCAAs) are essential for humans by promoting cell function and regulating protein metabolism [14]. BCAAs, especially leucine (Leu), have been studied because of their cell-signalling properties; they can stimulate protein synthesis [14] and decrease protein catabolism $[6,14,15]$. The oral administration of exogenous leucine stimulates protein synthesis in isolated or perfused rat muscles in vivo [16]. Moreover, clinical trials and studies in animals have shown that supplementation with BCAAs increases the balance of nitrogen and improves health after tissue damage, such as that due to burns, radiation, post-surgical stress, sepsis and cancer [17]. Studies have shown that the use of complementary therapies, as nutritional supplementation, improves the clinical status and especially the quality of life of cancer patients [18-21]. Meanwhile, maternal metabolism is directed to ensure the nutritional supply for the foetus and adjust foetal growth, but the combination of the metabolic and biochemical changes during pregnancy and cancer jeopardises the foetus and mother. Based on this, and more importantly because there are few studies about the foetal consequences of cancer development, this study investigated the effects of Walker-tumour growth on protein catabolism in foetal muscle, especially on proteolytic enzymes, antioxidant enzymes and lipid peroxidation and examined whether nutritional supplementation with leucine modulated the damage effects on foetal growth.

\section{Methods \\ Animals}

We studied foetuses (20 days of gestational age) that were obtained from pregnant adult Wistar rats. Female Wistar rats (90 days old) were obtained from the Animal Facilities Centre/UNICAMP and received food and water ad libitum under controlled light-dark cycles (12/12 hours each) at a constant temperature $\left(22+2^{\circ} \mathrm{C}\right)$. The female rats were bred with adult males (4:1 proportion) in collective cages for 12 hours [22]. After the first day of pregnancy was determined by vaginal smears, the pregnant rats were distributed into groups that either received or did not receive a tumour implant and were either administered nutritional supplementation or administered normal diet. Walker carcinoma 256 tumour cells $\left(2.5 \times 10^{5}\right.$ viable cells counted using the trypan blue method) were injected subcutaneously on the $2^{\text {nd }}$ day of pregnancy into the right flank of the experimental rats. The pregnant rats in the control groups received an equivalent volume of saline solution $(0.5 \mathrm{~mL})$ in the subcutaneous tissue of their right flanks. The handling of pregnant females with tumours was previously described in protocol \#657-1, which was approved by the Ethics in Animal Experiments (CEUA-IB-UNICAMP).

\section{Diet}

The semi-purified, isocaloric diets were defined as either normal (C - containing $18 \%$ protein [23]) or leucine-rich (L - containing $18 \%$ protein plus 3\% L-leucine, which represents a high percentage of this amino acid). Both diets contained $70 \%$ carbohydrates (sucrose, starch and dextrin), 7\% fat (soybean oil) and 5\% fibre (micro-cellulose purified). The diets were supplemented with a mixture of vitamins, minerals, cysteine and choline. The control diet contained 1.6\% L-leucine, and the leucinerich diet contained $4.6 \%$ L-leucine; these diets were identical to those used in our previous experimental studies [5,24-26].

\section{Experimental protocol}

The pregnant rats were distributed into 6 experimental groups according to tumour implant status and nutritional supplementation. Pair-fed groups were created to evaluate the effects of food intake reduction observed in tumour-bearing groups [27,28]. At least three foetuses per mother were collected to generate a pooled sample (3 foetuses/dam) for each group. The minimum number of mothers per group was at least eight animals. 


\section{Groups}

- Rat foetuses (C) from pregnant rats subjected to a normal diet.

- Rat foetuses (L) from pregnant rats subjected to a leucine-rich diet.

- Rat foetuses (W) from Walker tumour-bearing pregnant rats subjected to a normal diet.

- Rat foetuses (LW) from Walker tumour-bearing pregnant rats subjected to a leucine-rich diet.

- Foetuses from pair-fed pregnant rats $(\mathrm{Cp})$ subjected to the normal diet and paired with group W.

- Foetuses from pair-fed pregnant rats (Lp) subjected to a leucine-rich diet and paired with group LW.

The pregnant rats were maintained in collective cages during the experimental period, except for the pair-fed rats, which remained in metabolic cages and received food intake in accordance with the tumour-bearing groups, as previously determined in our lab studies [4]. After 20 days of pregnancy, the rats were sacrificed by cervical dislocation, and the foetuses and placentas were removed, dissected and weighed. The gastrocnemius foetal muscles were dissected and weighed to assess protein synthesis and degradation, and the activities of oxidative stress enzymes and malondialdehyde were assayed in foetal muscles. The foetal muscle homogenates were also analysed for the following enzyme activities related to the protein degradation process: the chymotrypsin-like enzyme of the ubiquitin-proteasome pathway, the cathepsin enzyme of the lysosomal pathway and the calpain enzyme of the calcium-dependent pathway. We also evaluated the expression of the $20 \mathrm{~S}$ subunit of the ubiquitin-proteasome system.

\section{Protein synthesis and degradation analyses}

The synthesis and degradation of proteins was assessed in pooled, foetal gastrocnemius muscles from each mother. For statistical analysis, the number of pregnant rats was at least 8 for the control groups and 10 to 12 for the tumour-bearing groups.

Protein synthesis assays were performed using methods that were previously adapted in our laboratory $[6,28,29]$. Pooled gastrocnemius muscles from both posterior paws of the foetuses (at least 3 foetuses per mother and were used at least 8 mothers per group) were dissected, placed in tubes for perfusion with KHB buffer (Krebs-Henseleit bicarbonate, $110 \mathrm{mM} \mathrm{NaCl}$, $25 \mathrm{mM} \mathrm{NaHCO} 3,3.4 \mathrm{mM} \mathrm{KCl}, 1 \mathrm{mM} \mathrm{CaCl}, 1 \mathrm{mM}$ $\mathrm{MgSO}_{4}$ and $1 \mathrm{mM} \mathrm{KH} \mathrm{PO}_{4} ; \mathrm{pH}$ 7.4) supplemented with $5.5 \mathrm{mM}$ glucose and $0.01 \%(\mathrm{w} / \mathrm{v})$ albumin and incubated at $37^{\circ} \mathrm{C}$ under continuous agitation in a $95 \% \mathrm{O}_{2}$ and $5 \%$ $\mathrm{CO}_{2}$ environment for 30 minutes. After this period, fresh KHB buffer supplemented with $5 \mu \mathrm{Ci}$ of $\mathrm{L}\left[{ }^{3} \mathrm{H}\right]-$ phenylalanine (Amersham, UK) and $60 \mathrm{mM}$ cold phenylalanine was added. After 2 hours of incubation, the muscles were removed from the medium, dried, weighed, frozen in liquid nitrogen and stored at $-80^{\circ} \mathrm{C}$. The muscles were homogenised in 30\% trichloroacetic acid (TCA) and centrifuged at $11,000 \times g$ for $15 \mathrm{~min}$ at $4^{\circ} \mathrm{C}$. The resulting pellet was washed twice with TCA $(10 \%)$ to eliminate the radioactivity of the supernatant. The pellet was treated with $1 \mathrm{~N} \mathrm{NaOH}$ and incubated at $40^{\circ} \mathrm{C}$ for 30 minutes. The protein content of the aliquots was then analysed [30], and the total $\beta$ emission radioactivity was assessed by liquid scintillation using beta-counting equipment (Beckman LS 6000 TA, Fullerton, CA, USA). The rates of protein synthesis, expressed as nanomoles of phenylalanine incorporated per hour per milligram of muscle protein, were calculated by dividing the amount of radioactivity incorporated into the foetal muscle protein over a $1-h$ period by the specific radioactivity of the phenylalanine in the incubation medium.

A protein degradation assay was also adapted by our laboratory [31] by measuring the amount of tyrosine that was released into the muscle incubation solution. Each pooled foetal gastrocnemius muscle sample ( 3 foetuses per mother/group) was incubated for $30 \mathrm{~min}$ at $37^{\circ} \mathrm{C}$ in RPMI 1640 medium. After this period, the muscles were incubated in $\mathrm{KHB}$ solution containing cycloheximide (a protein synthesis inhibitor) for 2 hours at $37^{\circ} \mathrm{C}$ in a $5 \% \mathrm{CO}_{2}$ and $95 \% \mathrm{O}_{2}$ environment. After incubation, the medium aliquots were treated with $30 \%$ TCA and centrifuged at $4,500 \times g$ for $10 \mathrm{~min}$ to assess the tyrosine content using a fluorometric assay utilising 20\% 1-nitroso2-naphthol reagent and nitric acid [32].

\section{Biochemical assays to assess the muscle proteolytic pathways and oxidative stress}

The foetal gastrocnemius muscle samples were homogenised in homogenising buffer $(20 \mathrm{mM}$ Tris, $1 \mathrm{mM}$ DTT, $2 \mathrm{mM}$ ATP and $5 \mathrm{mM} \mathrm{MgCl}_{2}$ ), resolved on $12 \%$ acrylamide-SDS gels and transferred to nitrocellulose membranes. A primary monoclonal antibody against the $20 \mathrm{~S}$ subunit of the proteasome (Affinity, England) (1:1,000 dilution) was used, and a secondary goat anti-mouse antibody was used to react with the primary antibody (Santa Cruz, USA) (1:1,000). The chemiluminescence reaction was performed using ECL reagents (Amersham), and the quantification of protein-band density was carried out using Image Capture (Amersham) and Gel Pro II-Plus software (Silver Spring, MD, USA).

The foetal muscle homogenates was also analysed for total protein content [30] and for chymotrypsin-like, cathepsin and calpain enzyme activity. Chymotrypsin-like activity, which is the proteolytic activity of the ubiquitinproteasome pathway, was evaluated using the substrate N-Succinyl-Leu-Leu-Val-Tyr-7-Amino-4-Methylcoumarin 
diluted in dimethyl sulfoxide (DMSO) and Tris buffer ( $\mathrm{pH}$ 8.0) and assessed using the fluorometric method at $360 \mathrm{~nm}$ excitation and $460 \mathrm{~nm}$ emission [33]. The activity of cathepsin, which is a lysosomal proteinase, was evaluated using a fluorometric method and the substrate benzyloxycarbonyl-phenylalanine- arginine 4-methyl-7coumarilamide at $340 \mathrm{~nm}$ excitation and $460 \mathrm{~nm}$ emission [34]. Calpain, which is a proteinase involved in calciumdependent protein degradation, was measured by incubating the samples in reaction buffer with casein for 5 minutes followed by the addition of $5 \mathrm{mM} \mathrm{CaCl}_{2}$ and subsequently reading the absorbance at $500 \mathrm{~nm}$ in a spectrophotometer according to the previously described colourimetric methodology [34].

Aliquots of the muscle-homogenate supernatant were analysed for glutathione-S-transferase (GST) activity based on the conjugation of 1-chloro-2,4-dinitrobenzene (CDNB; Sigma) with glutathione, and the activity was expressed as nmol. $\mu \mathrm{g}$ protein ${ }^{-1} \cdot \mathrm{min}^{-1}$ using an extinction coefficient of 9.6 as previously described [35]. The catalase activity was measured as described by Cohen [36], and the results are expressed as $\mathrm{nmol} / \mathrm{min} / \mathrm{mg}$ protein. Alkaline phosphatase activity was measured using $37 \mathrm{mM}$ 4-nitrophenyl disodium phosphate (p- NPP) and expressed in $\mathrm{nmol} / \mathrm{min} / \mathrm{mg}$ protein [37]. The amount of the lipid peroxidation product, malondialdehyde (MDA), was determined by incubating the samples with MPO (n-methyl-2-phenylindole; Sigma) and measuring the absorbance at $590 \mathrm{~nm}$; the results are expressed as $\mathrm{nmol} \cdot \mu \mathrm{g}$ protein $^{-1}$ [38].

After decapitation, foetal blood was collected using a microcapillary tube and then centrifuged to assay the haematocrit and obtain the foetal serum. The total protein concentration in the foetal serum was determined using the Biuret test, which is a colourimetric reaction that was read at $540 \mathrm{~nm}$ [39]. The albumin concentration in the foetal serum was determined using colourimetric methodology by reading a bromocresol green reaction at $630 \mathrm{~nm}$ [40]. The glucose level was quantified using an enzymatic reaction based on glucose-oxidase [41].

\section{Statistical analysis}

The results are reported as the means and standard error. The data were analysed using two-way ANOVA tests to detect the effects of diet, tumours, and the pair-feeding scheme on the foetal parameters (weight, enzyme activities and protein synthesis and degradation). The comparisons within the control and tumourbearing groups were performed using one-way ANOVA followed by Bonferroni multiple-comparison tests [42]. The calculations were performed using GraphPad Prism 3.0 software (GraphPad Inc., San Diego, CA, USA), and values of $\mathrm{P}<0.05$ indicate statistical significance.

\section{Results}

In the present study, the foetuses of tumour-bearing pregnant rats suffered similar effects due to tumour growth as those observed in tumour-bearing animals $[5,6,15,25,27]$. The weight of the foetuses in the $\mathrm{W}$ and LW groups was reduced (Figure 1A), and in this case the tumour effects account for $83 \%$ of the total variation, indicating that this low foetal weight is extremely significant. Consistent with this reduced foetal weight, the ratio of the foetal weight to the placental weight, which is indicative of the efficiency of placental transport, was decreased in both tumour-bearing groups and in the leucine pair-fed foetuses, especially when compared to the control rats (Figure 1B). These data show that the tumours and the pair-feeding scheme accounted for this impaired effect $(\mathrm{P}<0.0002)$. The reduction in foetal weight occurred in parallel with the group with the lowest concentration of total foetal serum protein, group W, which was $27 \%$ lower than that of the control group, $\mathrm{C}$ (Figure 1C). In contrast, the total foetal serum protein of the LW group was similar to that of the control group (C) and higher than that of the $\mathrm{W}$ group $(\mathrm{P}=0.0029)$. The serum albumin levels of the rats in the tumourbearing group (W) were reduced by approximately $31 \%$ compared to those in group LW $(\mathrm{P}<0.0001)$, which had a similar value to that of the control group (Figure 1D). Although the albumin-serum content was $20 \%$ higher in group L (under nutritional supplementation) than in group $\mathrm{C}$, the leucine-rich diet did not prevent the reduction in albumin levels in the foetuses from tumour-bearing rats, as observed when comparing the LW and L groups (Figure 1D, P $<0.0001$ ). Similarly, we observed a reduction in glucose levels in tumour-bearing foetuses, and those in the $\mathrm{W}$ groups showed a severe decrease in glucose levels (Figure 1E). Furthermore, the haematocrit was reduced only in the W group (Figure 1F). These data show that diet accounted for $46.7 \%$ of the total variance $(\mathrm{P}<0.0001)$, modulating the effect of Walker tumour development.

Tumour growth affected anti-oxidative enzyme activities and increased lipid peroxidation (malondialdehyde) in foetal gastrocnemius muscles (Figure 2). Alkaline phosphatase activity could be used to test muscle-cell function [37], which was decreased in the W foetuses, but leucine supplementation led to a similar level in the LW group. In contrast, the $\mathrm{L}, \mathrm{Cp}$ and $\mathrm{Lp}$ groups displayed increases in alkaline phosphatase activity compared to the control or tumour-bearing groups (Figure 2A). In comparison to the $\mathrm{C}$ group, glutathione$\mathrm{S}$-transferase activity was reduced in the $\mathrm{W}$ group but was similar in the LW group and increased in the L, Cp and Lp groups (Figure 2B). Catalase activity increased significantly only in the $\mathrm{W}$ group (Figure $2 \mathrm{C}$ ), and glutathione levels tended to increase only in the $\mathrm{W}$ group 


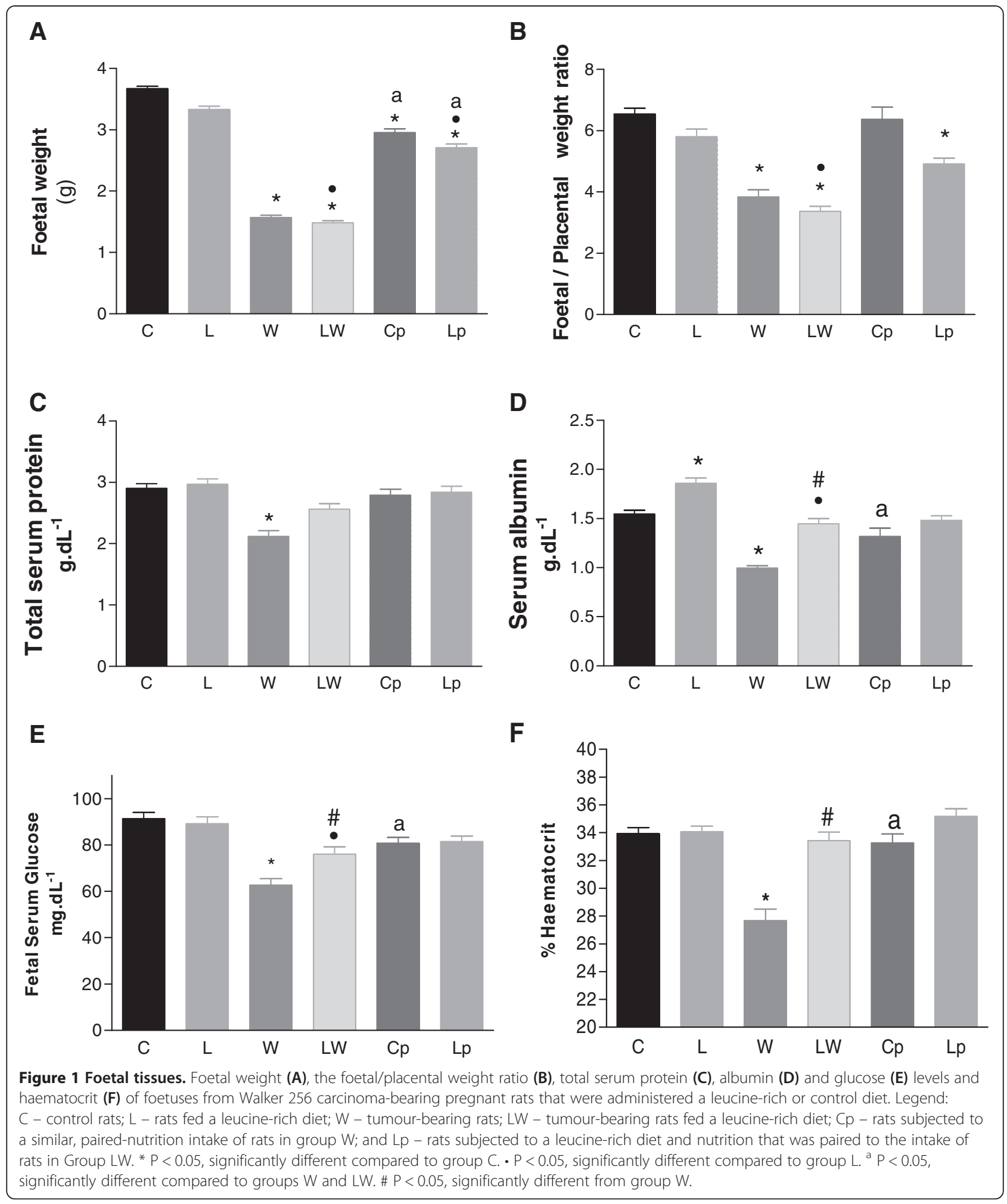

(Figure 2D). The product of oxidative stress, as expressed by the malondialdehyde level, increased only in the $\mathrm{W}$ group (Figure 2E), and the MDA/GST ratio was increased 3-fold in the W group compared to the LW group (Figure 2F). These data show that diet accounted for $27 \%$ of the total variance in enzyme activity, modulating the tumour changes to foetal antioxidant enzyme activities. 


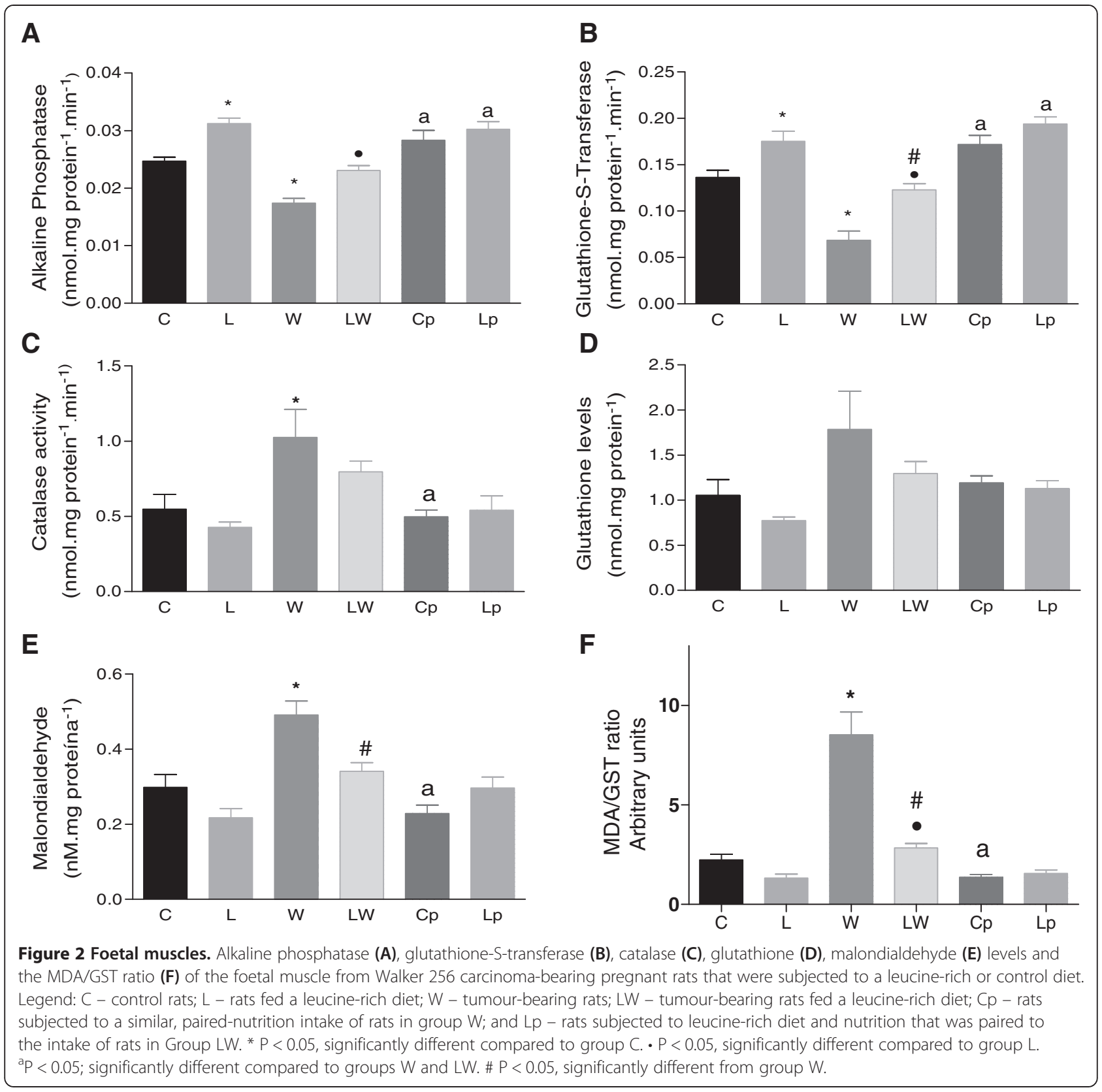

The total muscle protein content (Figure 3A) was decreased in both of the Walker tumour-bearing groups (W and LW) compared to the control groups (C and L). Despite the food restriction that was imposed by pair feeding, no differences in the foetal muscle protein content in the pair-fed groups ( $\mathrm{Cp}$ and $\mathrm{Lp}$ ) were observed. Foetal muscle protein synthesis, as determined by the incorporation of phenylalanine ( $\left.\mathrm{L}-\left[{ }^{3} \mathrm{H}\right]-\mathrm{Phe}\right)$, was approximately $27 \%$ lower in the foetuses of tumour-bearing pregnant rats $(\mathrm{W})$ than in the $\mathrm{LW}$ group $(\mathrm{P}=0.0103)$ and other groups (Figure 3B). As a result of leucine supplementation, muscle protein synthesis recovered in the LW group, and this change was significantly different from that of the $\mathrm{W}$ group; diet significantly modulated the tumour effect $(P=0.0005)$. In addition, the malnutrition factor that was imposed by food restriction, measured in the pair-fed groups (Cp and Lp), had no effect on the protein synthesis process (Figure 3B).

Foetal muscle protein degradation was evaluated by the amount of released tyrosine and was approximately $31 \%$ higher in the $\mathrm{W}$ group than in the control group $\mathrm{C}$ (Figure $3 \mathrm{C}$ ); in this case, the diet also accounted for a significant modulation of tumour effect $(P=0.0038)$. The chymotrypsin-like enzymatic activity, which is the catalytic portion of the ubiquitin-proteasome, was increased approximately 3.9-fold in group W, and despite 


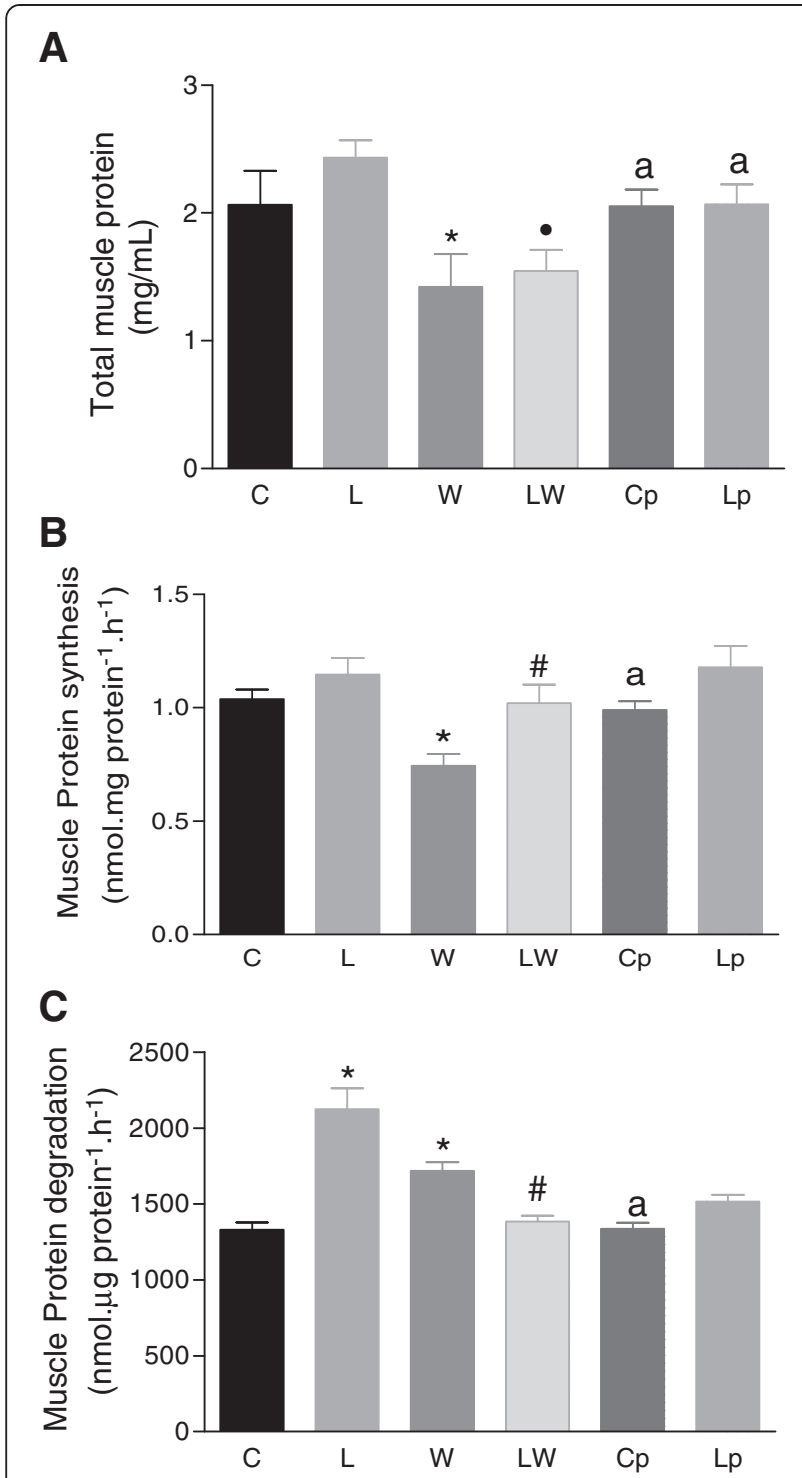

Figure 3 Foetal muscle protein synthesis and degradation. Total foetal muscle protein $\left(\mu \mathrm{g} \cdot \mathrm{mg}^{-1}\right)(\mathbf{A})$, muscle protein synthesis $\left(\mathrm{nmol} \cdot \mu \mathrm{g} \operatorname{protein}^{-1} \cdot \mathrm{h}^{-1}\right)$ (B) and muscle protein degradation $\left(\mathrm{nmol} \cdot \mu \mathrm{g}\right.$ protein $\left.^{-1} \cdot \mathrm{h}^{-1}\right)(\mathbf{C})$ in foetuses of tumour-bearing pregnant rats that were subjected to a leucine-rich or control diet. Protein synthesis was assessed by measuring phenylalanine incorporation (for details, see Methods), and protein degradation was assessed by the amount of tyrosine that was released from perfused muscle (for details, see Methods). Legend: $C$ - control rats; $L$ - rats fed a leucine-rich diet; $W$ - tumour-bearing rats; LW - tumour-bearing rats fed a leucine-rich diet; $\mathrm{Cp}$ - rats subjected to a similar, pairednutrition intake of rats in Group W; and Lp - rats subjected to a leucine-rich diet and nutrition that was paired to the intake of the rats in Group LW. * $P<0.05$; significantly different compared to group $C . P<0.05$; significantly different compared to group $L$. ${ }^{a} \mathrm{P}<0.05$; significantly different compared to groups $\mathrm{W}$ or LW. $\# P<0.05$, significantly different from group $W$. having tumours, the foetuses from pregnant rats that received a leucine-rich diet (LW) showed a less-pronounced increase in the chymotrypsin-like activity compared to the rats in group W. These differences were near statistical significance (Figure 4A; $\mathrm{P}=0.0803$ ). The pair-fed groups (Cp and Lp) showed an increase in chymotrypsin-like enzyme activity that was similar to that observed in the LW group when compared to the L group. Furthermore, the expression of the $20 \mathrm{~S}$ subunit of the ubiquitin-proteasome was decreased in the tumour-bearing groups (W and LW) and the pair-fed groups (Cp and Lp) (Figure 4B). Cathepsin H, which is one of the enzymes involved in the lysosomal proteolytic pathway, showed significantly increased activity in the W group, but this increase was less pronounced in the LW group (Figure $4 \mathrm{C})(\mathrm{P}<0.047)$; in this case, the diet modulated the effect of tumour growth. The calciumdependent proteolytic pathway showed no difference in its calpain activity between the tumour-bearing groups when compared to the $\mathrm{C}$ group, but the $\mathrm{L}$ and Lp groups showed decreased activity in relation to the values observed in group $\mathrm{C}$ rats (Figure 4D).

\section{Discussion}

Maternal physiological adaptations are impaired by cancer development and can lead to impaired foetal growth and development. Here, we clearly show that in the presence of Walker-256 tumour growth, foetal development was jeopardised, especially with respect to muscle protein metabolism linked to increased proteolysis and inhibited protein synthesis. These effects were likely associated with the lack of an anti-oxidative response, which reduced foetal weight. More importantly, we observed that nutritional supplementation with leucine led to a marked modulatory effect that minimised foetal proteolysis, maintained the balance of similar levels of protein synthesis and degradation, and restored the antioxidant responses.

Previous studies found that the presence of a tumour affected foetal weight $[4,5]$. This decrease in foetal weight was related to a reduction in placental weight, which may be related to changes in placental tissue, and decreased the foetal/placental weight ratio (Figure 1), leading to impaired foetal development. Foetal growth in rats is more intense during the third phase of pregnancy $\left(19^{\text {th }}-21^{\text {st }}\right.$ day $)$, which coincides with the greatest tumour weight $[3,5]$. The high activity of tumour cells that promotes exponential growth occurs during the same period of foetal growth. Thus, we verified that, at the time points when the tumour weighed approximately 10 to $12 \%$ of the maternal body weight, the $\mathrm{W}$ foetuses also displayed reductions in body weight, total serum protein, albumin and glucose that was coupled with a decline in muscle protein synthesis and increased 


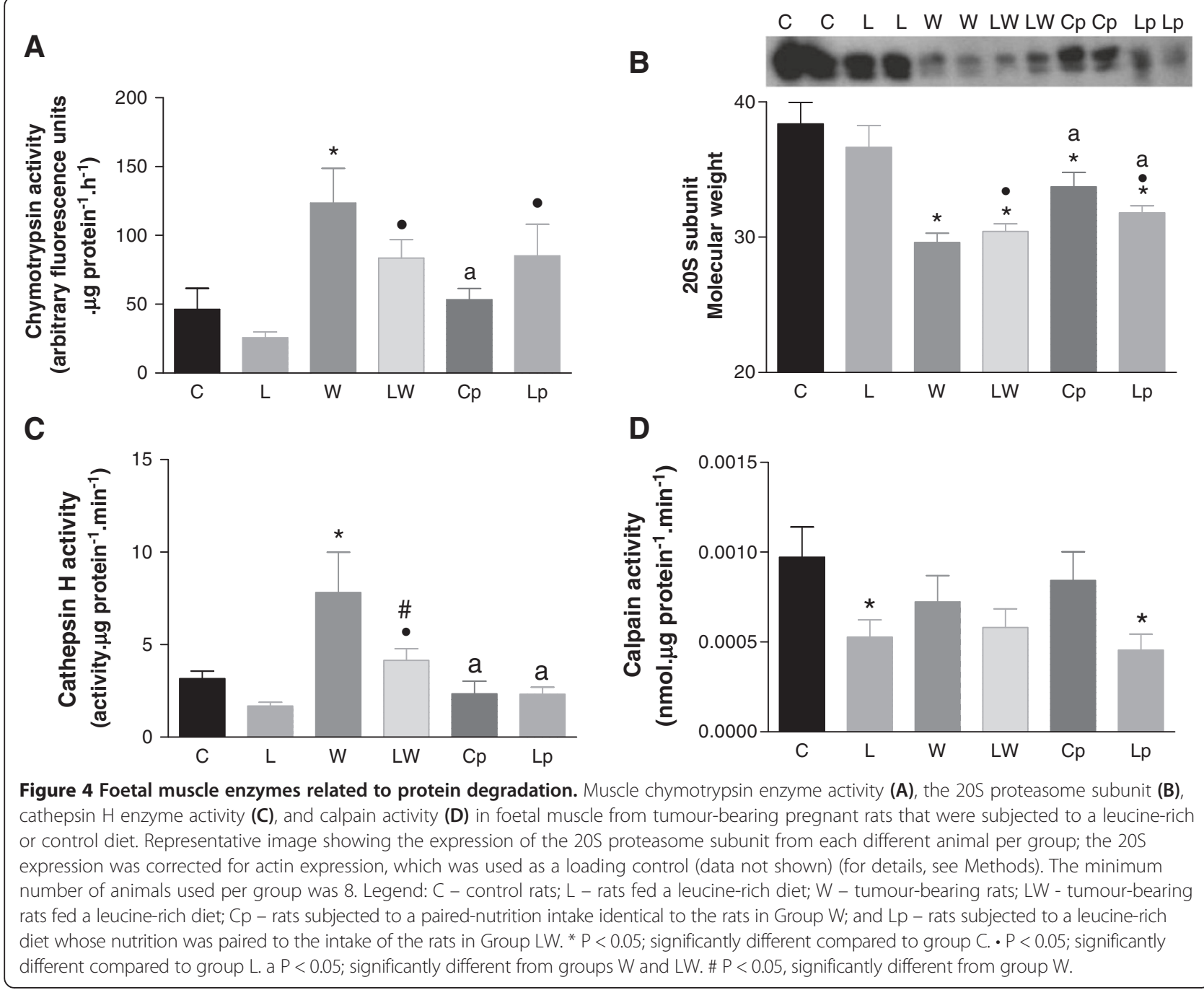

proteolysis. All of these findings are also the main metabolic changes that occur during tumourigenesis [25], as was found in the group W foetuses. Proteolysis is the main process during cancer-cachexia, and this can be assessed by a decrease in albumin content, followed by the catabolism of skeletal muscle cells, promoting atrophy and apoptosis $[43,44]$. Although the total muscle protein decreased in both of the tumour-bearing groups (W and LW), a leucine-rich diet maintained protein synthesis and reduced protein degradation in the LW group. This observation suggests that the LW group had a less intense catabolism of lean body mass, as was verified in the W group, which was likely related to the degradation of foetal muscle protein that was enhanced by oxidative stress $[38,45]$. According to our previous studies, lean body mass was reduced during tumour growth, and dietary supplementation with leucine minimised this loss $[3,5,8,24]$. Intense protein catabolism, primarily in the skeletal muscle, may have provided substrates, predominantly amino acids and gluconeogenic substrates, to be used by neoplastic cells $[25,46,47]$. Consequently, it is thought that tumour development induces a deviation of nutrients from the placenta and foetus (which is the reason for the decrease in foetal weight and reduction in the foetus/placenta ratio that is associated with increased protein degradation and oxidative stress). In parallel, the foetuses from mothers that were subjected to graduated food restriction ( $\mathrm{Cp}$ and $\mathrm{Lp}$ ) showed reduced weight, but their serum parameters and total muscle protein were similar to those of the control group animals. Nutritional supplements are particularly important for foetal viability and foetus/placenta unity, but foetuses have the capacity to adapt metabolically to acute and chronic changes in maternal and foetal serum nutrients content $[48,49]$. In contrast, we show that foetuses from tumour-bearing mothers, primarily those in group W, were not able to efficiently adapt their metabolism under cancer conditions compared to those under food restriction, as found in pair-fed foetuses (Cp). This fact may be related to the action of substances 
that are produced by cancer cells, as we have previously reported [4,7,50,51]. Carbo and colleagues [52] found deficits in the amino acid mobilisation of foetuses in pregnant rats that received tumour necrosis factor during pregnancy, and this was associated with decreased placental blood flow due to the action of this cytokine. We previously verified that pregnant rats that were injected with ascitic liquid (obtained from tumourbearing animals without tumour cells) exhibited an increase in foetal reabsorption and a reduction in foetal and placental weight; similar deleterious effects were found in tumour-bearing mothers $[3,4,50]$. In these experiments, we proposed that these changes were induced by substances produced by cancer cells and did not result from only the effect of reducing nutrients, as was observed in this study when comparing the $\mathrm{W}$ and $\mathrm{Cp}$ foetuses.

Pregnancy changes, especially the increase in muscle protein breakdown, are related to the effects of the tumour on the body. In the cancer host, the catabolism that is associated with the reduction and/or maintenance of the protein synthesis process is increased $[24,53]$ and is related to increased oxidative stress $[38,45,50]$. In this case, the foetuses from the rats in group W displayed reduced protein synthesis, which was also associated with an increase in proteolysis caused by the activation of proteolytic systems and a high oxidative stress process. The ubiquitin-proteasome pathway can be modulated by a leucine-rich diet $[6,8]$. As has been reported in many other studies, the activity of this process was higher and more widely observed in foetal cells. The $20 \mathrm{~S}$ subunit, which comprises the catalytic core of the ubiquitin-proteasome proteolytic pathway, is most likely involved in protein turnover, leading to differentiation and development of embryonic and foetal tissues. However, we showed that although the 20S subunit was expressed at lower levels in the W and LW foetuses, the greater chymotrypsin-like activity and oxidative stress that were found in group W were sufficient to promote protein wasting in those foetuses. More importantly, under leucine nutritional supplementation, the LW foetuses showed less increased protein degradation because leucine diminished the increase in chymotrypsin activity and maintained the cathepsin enzyme while increasing the antioxidant response; these results suggest a beneficial effect of leucine in minimising proteolysis. Moreover, tumour growth produces alterations that affect placental metabolism and interact with the placenta-foetus, as evidenced by intrauterine growth restriction with increased foetal-muscle catabolism $[3,4,6,24,52]$.

Nutritional supplementation with leucine provides several benefits by activating cellular synthesis processes $[6,24,25]$. These data suggest that the foetuses that received nutritional leucine supplementation, even those that were suffering from their mother's tumours, showed diminished deleterious effects due to tumour growth compared to those that did not receive leucine; the foetuses in the LW group had similar muscle protein synthesis to the control foetuses, and more importantly, the process of protein catabolism was minimised and was equal to that of the control group $[4,5,54]$. Further studies are underway in our laboratory to determine whether leucine supplementation can counteract the damage to foetal growth during cancer development and the mechanism underlying this effect. These data indicate the importance of co-adjuvant therapy in improving the state of host responses to clinical treatment and particularly the importance of leucine supplementation, which has a positive effect on the host mother and on foetal development.

\section{Conclusions}

The nutritional supplementation of a leucine-rich diet induced protein synthesis in the skeletal muscle of foetuses of pregnant, tumour-bearing rats. This effect may be due to minimisation of protein catabolism and enhancement of the anti-oxidative response.

\section{Competing interests \\ The authors declare that there is no competing interest that could be perceived as prejudicing the impartiality of the research reported.}

\section{Authors' contributions}

BLGC contributed to the data collection, analysis, data interpretation and manuscript preparation. MCCGM conceived the study and its design and coordinated the work and the preparation of the manuscript. Both authors read and approved the final manuscript.

\section{Acknowledgments}

The authors gratefully thank Dr. J. Marcondes for computational support and Dr. M. A. R. Mello for insightful discussions. Carbohydrates and dextrin were donated by Corn Products (Sao Paulo, Brazil), and amino acids were donated by Ajinomoto Brasil (Sao Paulo, Brazil). The manuscript was edited for proper English language by American Journal Experts (Certificate Verification Key: 41C9-7AE0-613C-243B-2692). This experimental work was supported by Fundação de Amparo a Pesquisa do Estado de São Paulo (FAPESP, \#2010/ 00209-9) and the Conselho Nacional de Desenvolvimento Cientifico e Tecnologico (CNPq \# 304604/2010-0). B.G.C. is a research fellow supported by Fundação de Amparo a Pesquisa do Estado de São Paulo, grant \#2011/ 08276-0, São Paulo, Brazil.

Received: 20 September 2013 Accepted: 29 December 2013 Published: 3 January 2014

\section{References}

1. Pavlidis N, Pentheroudakis G: The pregnant mother with breast cancer: diagnostic and therapeutic management. Cancer Treat Rev 2005 31(6):439-447.

2. Azim HA Jr, Pavlidis N, Peccatori FA: Treatment of the pregnant mother with cancer: a systematic review on the use of cytotoxic, endocrine, targeted agents and immunotherapy during pregnancy. Part II: hematological tumors. Cancer Treat Rev 2010, 36(2):110-121.

3. Toledo MT, Ventrucci G, Marcondes MCCG: Cancer during pregnancy alters the activity of rat placenta and enhances the expression of cleaved PARP, cytochrome-c and caspase 3. BMC Cancer 2006, 6:168-177.

4. Gomes-Marcondes MCC, Cury L, Curi R: Consequences of Walker 256 tumour growth for the placental/foetal development in rats. Cancer Res Ther Control 1998, 5:277-283. 
5. Ventrucci G, Mello MAR, Gomes-Marcondes MCC: Effect of a leucine-supplemented diet on body composition changes in pregnant rats bearing walker 256 tumor. Braz J Med Biol Res 2001 34(3):333-338.

6. Ventrucci G, Mello MAR, Gomes-Marcondes MCC: Proteasome activity is altered in skeletal muscle tissue of tumour-bearing rats fed a leucine-rich diet. Endocr Relat Cancer 2004, 11(4):887-895.

7. Viana LR, Gomes-Marcondes MC: Leucine-rich diet improves the serum amino acid profile and body composition of fetuses from tumor-bearing pregnant mice. Biol Reprod 2013, 88(5):121.

8. Ventrucci G, Mello MAR, Gomes-Marcondes MCC: Leucine-rich diet alters the eukaryotic translation initiation factors expression in skeletal muscle of tumour-bearing rats. BMC Cancer 2007, 7:42-52

9. Emery PW: Cachexia in experimental models. Nutrition 1999, 15(7-8):600-603.

10. Bennani-Baiti N, Walsh D: Animal models of the cancer anorexia-cachexia syndrome. Support Care Cancer 2011, 19(9):1451-1463.

11. Fowden AL, Forhead AJ, Ousey JC: Endocrine adaptations in the foal over the perinatal period. Equine Vet J 2012, 44:130-139.

12. Perkins AV: Endogenous anti-oxidants in pregnancy and preeclampsia. Aust N Z J Obstet Gynaecol 2006, 46(2):77-83.

13. Mantovani G, Madeddu C, Maccio A, Gramignano G, Lusso MR, Massa E, Astara G, Serpe R: Cancer-related anorexia/cachexia syndrome and oxidative stress: an innovative approach beyond current treatment. Cancer Epidemiol Biomarkers Prev 2004, 13(10):1651-1659.

14. Garlick PJ: The role of leucine in the regulation of protein metabolism. J Nutr 2005, 135(6):1553s-1556s.

15. Ventrucci G, Mello MA, Gomes-Marcondes MC: Leucine-rich diet alters the eukaryotic translation initiation factors expression in skeletal muscle of tumour-bearing rats. BMC Cancer 2007, 7:42

16. Norton LE, Layman DK: Leucine regulates translation initiation of protein synthesis in skeletal muscle after exercise. J Nutr 2006, 136(2):533s-537s.

17. Choudry HA, Pan M, Karinch AM, Souba WW: Branched-chain amino acid-enriched nutritional support in surgical and cancer patients. $J$ Nutr 2006, 136(1):314s-318s.

18. Kado K, Forsyth A, Patel PR, Schwartz JA: Dietary supplements and natural products in breast cancer trials. Front Biosci (Elite Ed) 2012, 4:546-567.

19. Hardy ML: Dietary supplement use in cancer care: help or harm. Hematol Oncol Clin North Am 2008, 22(4):581-617. vii.

20. Ishikawa T: Early administration of branched-chain amino acid granules. World J Gastroenterol 2012, 18(33):4486-4490.

21. Sun LC, Shih YL, Lu CY, Hsieh JS, Chuang JF, Chen FM, Ma CJ, Wang JY: Randomized, controlled study of branched chain amino acid-enriched total parenteral nutrition in malnourished patients with gastrointestinal cancer undergoing surgery. Am Surg 2008, 74(3):237-242.

22. Barker DJP: Maternal nutrition, fetal nutrition, and disease in later life. Nutrition 1997, 13(9):807-813.

23. Reeves PG, Nielsen FH, Fahey GC: Ain-93 purified diets for laboratory rodents - final report of the American institute of nutrition Ad Hoc writing committee on the reformulation of the Ain-76a rodent diet. J Nutr 1993, 123(11):1939-1951.

24. Ventrucci G, Silva LGR, Mello MAR, Marcondes MCCG: Effects of a leucine-rich diet on body composition during nutritional recovery in rats. Nutrition 2004, 20(2):213-217.

25. Gomes-Marcondes MCC, Ventrucci G, Toledo MT, Cury L, Cooper JC: A leucine-supplemented diet improved protein content of skeletal muscle in young tumor-bearing rats. Braz J Med Biol Res 2003, 36(11):1589-1594.

26. Salomao EM, Gomes-Marcondes MCC: Light aerobic physical exercise in combination with leucine and/or glutamine-rich diet can improve the body composition and muscle protein metabolism in young tumor-bearing rats. J Physiol Biochem 2012, 68(4):493-501.

27. Ventrucci G, de Mello MA, Gomes-Marcondes MC: Effects of leucine supplemented diet on intestinal absorption in tumor bearing pregnant rats. BMC Cancer 2002, 2:7.

28. Vary TC, Jefferson LS, Kimball SR: Amino acid-induced stimulation of translation initiation in rat skeletal muscle. Am J Physiol Endocrinol Metab 1999, 277(6):E1077-E1086.

29. Fedele MJ, Vary TC, Farrell PA: Plasticity in skeletal, cardiac, and smooth muscle - selected contribution: IGF-I antibody prevents increases in protein synthesis in epitrochlearis muscles from refed, diabetic rats. J Appl Physiol 2001, 90(3):1166-1173.
30. Lowry OH, Rosebrough NJ, Farr AL, Randall RJ: Protein measurement with the folin phenol reagent. J Biol Chem 1951, 193(1):265-275.

31. Lorite MJ, Thompson MG, Drake JL, Carling G, Tisdale MJ: Mechanism of muscle protein degradation induced by a cancer cachectic factor. Br J Cancer 1998, 78(7):850-856.

32. Waalkes TP, Udenfriend S: A fluorometric method for the estimation of tyrosine in plasma and tissues. J Lab Clin Med 1957, 50(5):733-736.

33. Barrett AJ: Fluorimetric assays for Cathepsin-B and Cathepsin- $\mathrm{H}$ with methylcoumarylamide substrates. Biochem J 1980, 187(3):909-912.

34. Jiang ST, Wang JH, Chang T, Chen CS: A continuous method for measuring calpain activity. Anal Biochem 1997, 244(2):233-238.

35. Habig WH, Pabst MJ, Jakoby WB: Glutathione S-transferases - first enzymatic step in mercapturic acid formation. J Biol Chem 1974, 249(22):7130-7139.

36. Cohen $G$, Dembiec D, Marcus J: Measurement of catalase activity in tissue extracts. Anal Biochem 1970, 34(1):30.

37. Martins MJ, Negrao MR, Hipolito-Reis C: Alkaline phosphatase from rat live and kidney is differentially modulated. Clin Biochem 2001, 34(6):463-468.

38. Gomes-Marcondes MCC, Tisdale MJ: Induction of protein catabolism and the ubiquitin-proteasome pathway by mild oxidative stress. Cancer Lett 2002, 180(1):69-74.

39. Gornall AG, Bardawill CJ, David MM: Determination of serum proteins by means of the biuret reaction. J Biol Chem 1949, 177(2):751-766.

40. Meulemans O: Determination of total protein in spinal fluid with sulphosalicylic acid and trichloroacetic acid. Clin Chim Acta 1960, 5(5):757-761.

41. Trinder P: Determination of blood glucose using 4-amino phenazone as oxygen acceptor. J Clin Pathol 1969, 22(2):246.

42. Gad SC: Statistic for toxicologists. In Principles and Methods of toxicology, 4th edition. New York: Raven Press; 2009:221-274.

43. Tisdale MJ: Cancer cachexia. Curr Opin Gastroenterol 2010, 26(2):146-151.

44. Suzuki H, Asakawa A, Amitani H, Nakamura N, Inui A: Cancer cachexiapathophysiology and management. J Gastroenterol 2013, 48(5):574-594.

45. Yano CL, Ventrucci G, Field WN, Tisdale MJ, Gomes-Marcondes MC: Metabolic and morphological alterations induced by proteolysisinducing factor from walker tumour-bearing rats in C2C12 myotubes. BMC Cancer 2008, 8:24.

46. Liu W, Glunde K, Bhujwalla ZM, Raman V, Sharma A, Phang JM: Proline oxidase promotes tumor cell survival in hypoxic tumor microenvironments. Cancer Res 2012, 72(14):3677-3686.

47. Fearon KC, Glass DJ, Guttridge DC: Cancer cachexia: mediators, signaling, and metabolic pathways. Cell Metab 2012, 16(2):153-166.

48. Hay WW: Recent observations on the regulation of fetal metabolism by glucose. J Physiol 2006, 572(1):17-24.

49. Cetin I, Antonazzo P: The role of the placenta in intrauterine growth restriction (IUGR). Z Geburtshilfe Neonatol 2009, 213(3):84-88.

50. Toledo MT, Ventrucci G, Gomes-Marcondes MC: Increased oxidative stress in the placenta tissue and cell culture of tumour-bearing pregnant rats. Placenta 2011, 32(11):859-864.

51. Toledo MT, Gomes Marcondes MC: Placental glycogen metabolism changes during walker tumour growth. Placenta 2004, 25(5):456-462

52. Carbo N, Lopezsoriano FJ, Argiles JM: Administration of tumor-necrosisfactor-alpha results in a decreased placental-transfer of amino-acids in the rat. Endocrinology 1995, 136(8):3579-3584.

53. Zhang GH, Jin BW, Li YP: C/EBP beta mediates tumour-induced ubiquitin ligase atrogin1/MAFbx upregulation and muscle wasting. EMBO J 2011, 30(20):4323-4335.

54. Aversa Z, Bonetto A, Costelli P, Minero VG, Penna F, Baccino FM, Lucia S, Fanelli FR, Muscaritoli M: beta-hydroxy-beta-methylbutyrate (HMB) attenuates muscle and body weight loss in experimental cancer cachexia. Int J Oncol 2011, 38(3):713-720.

doi:10.1186/1477-7827-12-2

Cite this article as: Cruz and Gomes-Marcondes: Leucine-rich diet

supplementation modulates foetal muscle protein metabolism impaired by Walker-256 tumour. Reproductive Biology and Endocrinology 2014 12:2. 